\title{
Hemograma e sobrevivência de camarões marinhos após silenciamento do WSSV por RNA de interferência
}

\author{
Cristhiane Guertler(1), Tailin Rieg(2), Claudio Humberto Mejía-Ruíz ${ }^{(3)}$, Maurício Lehmannn ${ }^{(4)}$, \\ Margherita Anna Barracco(1) e Luciane Maria Perazzolo(1)
}

\begin{abstract}
(1) Universidade Federal de Santa Catarina, Departamento de Biologia Celular, Embriologia e Genética, Laboratório de Imunologia Aplicada à Aquicultura, CEP 88040-900 Florianópolis, SC. E-mail: cristhianeguertler@yahoo.com.br, barracco@mbox1.ufsc.br, luciane@ccb.ufsc.br (2)Ministério da Aquicultura e Pesca, Rua Martinho Calado, № 21, CEP 88015-040 Florianópolis, SC. E-mail: tai.rieg@hotmail.com ${ }^{(3)}$ Centro de Investigaciones Biológicas del Noroeste, S.C. Mar Bermejo, no 195, Colonia Playa Palo de Santa Rita, Código Postal 23090, La Paz, México. E-mail: hmejia04@cibnor.mx (4)Instituto Federal Catarinense, Rodovia BR-280, Km 27, CEP 89245-000 Araquari, SC. E-mail: lehmann@brturbo.com.br
\end{abstract}

Resumo - O objetivo deste trabalho foi avaliar a proteção antiviral específica via RNA de interferência (RNAi) contra o vírus da síndrome da mancha-branca (WSSV), em camarões marinhos (Litopenaeus vannamei). Os camarões foram injetados com uma sequência dsRNA específica (vp28 do envelope viral), seguida por desafio com WSSV após 48 horas. Avaliaram-se o hemograma às $0,3,6,24,48$ e 72 horas após o desafio, e a taxa de mortalidade durante 30 dias. Nos animais tratados com dsRNA vp28, a infecção viral foi limitada, e a sobrevivência (73\%) e a "clearance" viral $(80 \%)$ foram maiores do que nos camarões infectados, não tratados, que apresentaram $100 \%$ de mortalidade em cinco dias. Nos camarões tratados com dsRNA, o hemograma diminuiu até 6 horas após o desafio, seguido por aumento, tendo atingido o nível normal em 72 horas. O tratamento com dsRNA vp28 limita a infecção nos camarões por WSSV, restaura as suas condições imunológicas e promove "clearance" viral na maioria dos sobreviventes. Esses resultados são indicativos de que dsRNA vp28 pode servir como ferramenta molecular para combater o WSSV e que o RNAi representa abordagem promissora para controlar doenças virais em camarões cultivados.

Termos para indexação: Litopenaeus vannamei, defesas antivirais, hemócitos totais, imunologia de crustáceos, vírus da mancha-branca.

\section{Hemogram and survival rate of marine shrimp after silencing of WSSV by RNA interference}

\begin{abstract}
The objective of this work was to evaluate the specific antiviral protection via RNA interference (RNAi) against the white spot syndrome virus (WSSV) in marine shrimp (Litopenaeus vannamei). Shrimp were injected with a dsRNA specific sequence (vp28 from the viral envelope), followed by challenge, with WSSV after 48 hours. The hemogram was evaluated at $0,3,6,24,48$, and 72 hours after challenge and the mortality rate during 30 days. In animals treated with vp28 dsRNA the viral infection was limited, and survival (73\%) and viral clearance (80\%) were higher than in infected, not treated shrimp, which showed $100 \%$ mortality within five days. In shrimp treated with dsRNA, the hemogram decreased until 6 hours after viral challenge, followed by an increase, reaching normal levels at 72 hours. The treatment with vp28 dsRNA limits WSSV infection in shrimp, restores their immune conditions, and promotes viral clearance in most survivors. These results indicate that vp28 dsRNA can serve as a molecular tool for combating WSSV, and that RNAi represents a promising approach for the control of viral diseases in cultured shrimp.
\end{abstract}

Index terms: Litopenaeus vannamei, antiviral responses, total hemocytes, crustacean immunology, white spot virus.

\section{Introdução}

$\mathrm{O}$ vírus da síndrome da mancha-branca (WSSV) é o agente etiológico da virose mais avassaladora da história da carcinicultura (Escobedo-Bonilla et al., 2008), responsável por mortalidades que podem chegar a $100 \%$, de 2 a 7 dias, após detectados os primeiros sinais clínicos (Chou et al., 1995). No Brasil, os primeiros surtos dessa virose foram reportados em cultivos de camarões marinhos (Litopenaeus vannamei), em Santa Catarina, em 2004, onde causou mortalidades de $90 \%$ e prejuízos na ordem de 3 milhões de dólares (Seiffert 
et al., 2006). O WSSV é um vírus envelopado, com genoma de DNA dupla fita circular, baciliforme (Van Hulten et al., 2001; Yang et al., 2001; Chen et al., 2002), pertencente ao gênero Whispovirus da família Nimaviridae (Mayo, 2002).

OWSSVé extremamente virulento e patogênico para todas as espécies de peneídeos cultiváveis e, também, para outros crustáceos decápodas, como caranguejos e lagostins (Lo et al., 1996), pois infecta as células de origem ectodermal e mesodermal (Wongteerasupaya et al., 1995), que incluem os hemócitos, células imunocompetentes dos crustáceos (Wang et al., 2002). Os crustáceos, diferentemente dos vertebrados, contam apenas com um sistema imune inato para protegê-los contra microrganismos e parasitas invasores. O contato com os microrganismos ativa respostas celulares e humorais que atuam de maneira integrada para protegê-los e garantir a sua integridade corpórea e homeostática (Barracco et al., 2008).

Entre os principais mecanismos de defesa antivirais em invertebrados, destaca-se o sistema antiviral mediado por RNA de interferência (RNAi), que representa um antigo e bem conservado mecanismo de defesa contra vírus e "transposons", presente em todos os organismos pluricelulares, como plantas, fungos, invertebrados e vertebrados (Hannon, 2002; Obbard et al., 2009). A ativação deste mecanismo inicia-se pelo processamento de precursores longos de RNA dupla fita (dsRNA), ou regiões de RNA fita simples em forma de grampo (RNAs do tipo "hairpin" ou hRNA), pela endoribonuclease Dicer, que os cliva em pequenos RNAs duplex (21-25 nucleotídeos), denominados de "short interfering" RNA (siRNAs) e microRNAs (miRNAs), respectivamente (Aliyari \& Ding, 2009).

No caso de uma infecção viral, os siRNAs são, também, conhecidos por "viral" RNA (viRNA). Estes pequenos RNAs fornecem as sequências específicas para um complexo multiproteico de silenciamento induzido por RNA ou RNA-"induced silencing complex", que dirige uma degradação específica ou a repressão da tradução do RNAm com regiões complementares à sequência do dsRNA/hRNA desencadeante. Em última análise, a degradação do RNAm impossibilita que a proteína correspondente seja traduzida.

Em L. vannamei , a primeira evidência da existência de uma defesa antiviral específica via RNAi foi demonstrada por Robalino et al. (2005). Desde então, vários estudos têm continuado a utilizar esta técnica para limitar diferentes infecções virais de camarões cultivados, a partir de injeções de dsRNA com sequências homólogas aos RNAm de proteínas estruturais dos vírus (Shekhar \& Lu, 2009).

Uma vez que os crustáceos não podem ser vacinados, como os vertebrados, pois não apresentam sistema imune adaptativo que os proteja de maneira antígeno-específica e em longo prazo, é imperativo e urgente que se busquem métodos alternativos e efetivos que limitem ou impeçam a progressão das infecções virais nos camarões e evitem as enormes perdas econômicas na carcinicultura.

O objetivo deste trabalho foi avaliar a proteção antiviral específica via RNA de interferência (RNAi) contra o vírus da síndrome da mancha-branca (WSSV), em camarões marinhos (Litopenaeus vannamei).

\section{Material e Métodos}

O experimento foi conduzido no Instituto Federal de Educação, Ciência e Tecnologia Catarinense, Campus Araquari, SC, em 2009. Camarões juvenis ( $\mathrm{n}=162$, $12 \pm 1,5 \mathrm{~g}$ ), em período de intermuda, foram adquiridos da fazenda experimental Yakult/UFSC, Balneário Barra do Sul, SC. Os animais foram mantidos por 30 dias em tanques de $50 \mathrm{~L}$ ( $\mathrm{n}=18$, por tanque) e alimentados uma vez ao dia, com ração comercial. Antes do início do experimento, a hemolinfa dos animais foi coletada para verificar a presença do WSSV por "nested" PCR. Somente animais livres de WSSV foram utilizados no experimento.

A solução de inóculo de WSSV foi preparada segundo metodologia adaptada de Prior et al. (2003). $\mathrm{O}$ tecido muscular de camarões mortos, diagnosticados com WSSV, foi homogeneizado em tampão $(\mathrm{NaCl}$ $330 \mathrm{mmol} \mathrm{L}^{-1}$, Tris $\left.10 \mathrm{mmol} \mathrm{L}^{-1}, \mathrm{pH} 7,4\right)(1: 10 \mathrm{p} / \mathrm{v}) \mathrm{e}$, em seguida, centrifugado a $2.000 \mathrm{~g}$, por $20 \mathrm{~min}$ a $4^{\circ} \mathrm{C}$. O sobrenadante foi centrifugado a $9.000 \mathrm{~g}$, por $10 \mathrm{~min}$, a $4^{\circ} \mathrm{C}$, filtrado $(0,45 \mu \mathrm{m})$ e armazenado em nitrogênio líquido. Simultaneamente, um inóculo livre de WSSV foi preparado seguindo a mesma metodologia, porém com utilização de músculo de animais diagnosticados como WSSV negativo. A metodologia para a quantificação da carga viral do WSSV por PCR em tempo real foi realizada segundo protocolo descrito por Müller (2009). 
O RNA dupla fita foi sintetizado conforme protocolo preconizado pelo kit BLOCK-iT RNAi TOPO (Life Technologies do Brasil, Ltda., São Paulo, SP). A sequência gênica correspondente à proteína vp28 do WSSV foi amplificada por PCR (fragmento $610 \mathrm{pb}$ ), tendo-se utilizado os iniciadores VP28F3: 5'ATGGATCTTTCTTTC3' e VP28R3: 5'TTACTCGGTCTCAG3' sob condições de $94^{\circ} \mathrm{C}$ por 4 min, seguido por 33 ciclos $\left(94^{\circ} \mathrm{C}\right.$ por $1 \mathrm{~min}, 58^{\circ} \mathrm{C}$ por $1 \mathrm{~min}$ e $72^{\circ} \mathrm{C}$ por $1 \mathrm{~min}$ ) e $72^{\circ} \mathrm{C}$ por $7 \mathrm{~min}$ (Mejía-Ruíz et al., 2011).

Os camarões livres de WSSV foram aleatoriamente separados em três grupos experimentais, em triplicata (54 animais por grupo): grupo W (controle negativo), injetado intramuscularmente com tampão ( $\mathrm{NaCl} 330 \mathrm{mmol} \mathrm{L}^{-1}$, Tris $10 \mathrm{mmol} \mathrm{L}^{-1}, \mathrm{pH} \mathrm{7,4)} \mathrm{e,}$ posteriormente, com inóculo puro de tecido de camarão livre de WSSV; grupo W+ (grupo infectado), injetado com tampão e infectado com inóculo puro de WSSV $\left(1,3 \times 10^{7}\right.$ partículas virais por animal); e grupo dsRNA vp28/W+, injetado com $1 \mu \mathrm{g}$ dsRNA vp28 por $3 \mathrm{~g}$ de peso vivo e infectado com WSSV. Os animais foram injetados com $50 \mu$ l (tampão salina, inóculo viral e dsRNA vp28) entre o primeiro segmento abdominal e o cefalotórax, na região dorsal, e foram mantidos no sistema experimental por 30 dias. A coleta de hemolinfa para os hemogramas dos animais $(\mathrm{n}=162)$ de todos os grupos foi realizada às 0 (antes do desafio; primeira coleta), 3, 6, 24, 48 e 72 horas após o desafio (segunda à sexta coletas). Em cada tempo e para cada tratamento, foram coletados três "pools" de três animais cada um (Figura 1).

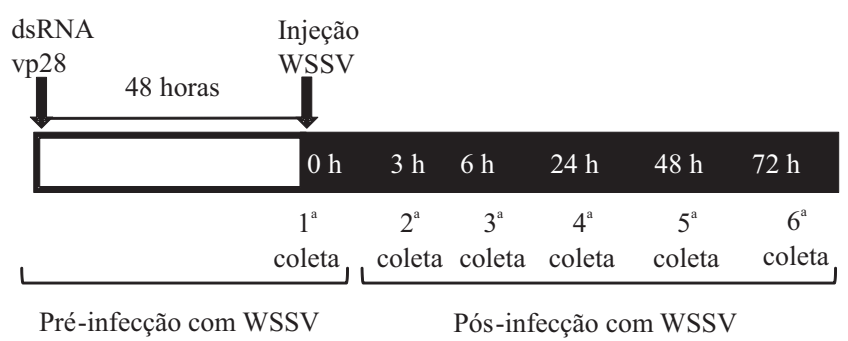

Figura 1. Esquema explicativo do desenho experimental. No período de pré-infecção, os animais foram injetados com tampão (grupos W- e W+) ou com dsRNA vp28 (grupo dsRNA vp28/W+) e, após 48 horas, infectados (W+ e dsRNA vp28/W+) ou não (W-) com o vírus da síndrome da mancha-branca (WSSV). Coletas de hemolinfa foram feitas nos tempos: 0 hora (antes do desafio) e 3, 6, 24, 48 e 72 horas após o desafio.
A percentagem da mortalidade dos animais foi monitorada diariamente, durante 30 dias, a partir do desafio viral, para avaliar a proteção antiviral específica dos camarões pelo dsRNA vp28. Além disso, a hemolinfa dos animais sobreviventes e os pleópodes dos animais mortos foram coletados para verificar a presença do WSSV por PCR.

A hemolinfa foi coletada em solução anticoagulante de Alsever modificada (MAS) $\left(336 \mathrm{mmol} \mathrm{L}^{-1} \mathrm{NaCl}\right.$, $115 \mathrm{mmol} \mathrm{L}^{-1}$ glicose, $27 \mathrm{mmol} \mathrm{L}^{-1}$ citrato de sódio, $9 \mathrm{mmol} \mathrm{L}^{-1}$ EDTA, pH 7,2) (1:2), na região ventral do abdômen, tendo-se utilizado seringa $(1 \mathrm{~mL})$ com agulha $(13 \times 0,4 \mathrm{~mm})$ que foi inserida entre o último esternito cefalotorácico e o primeiro abdominal. Parte dos hemócitos coletados foi utilizada para detectar a presença do WSSV por PCR, e uma alíquota de hemolinfa total foi separada e armazenada em formol MAS 4\% (1:3) para análise dos hemogramas. A contagem total de hemócitos (CTH) foi estimada em câmara de Neubauer, de modo semelhante à realizada para glóbulos brancos (Beçak \& Paulete, 1976).

A extração do DNA genômico de pleópodes e hemócitos foi realizada em DNAzol (Life Technologies do Brasil, Ltda., São Paulo, SP) de acordo com instruções do fabricante. A pureza das amostras foi avaliada em espectrofotômetro $\left(\mathrm{A}_{260 / 280 \mathrm{~nm}}\right)$ WPA Biowave II, (Biochrom Ltd., Cambridge, Reino Unido). A presença de WSSV nos animais de cada grupo experimental foi avaliada às 3, 6, 24, 48 e 72 horas após a injeção, por PCR convencional (um passo) e por "nested" PCR (dois passos). Para isso, foram utilizados os iniciadores recomendados pela World Organisation for Animal Health (2006) - WSSV146Fw1: 5'ACT ACTAACTTCAGCCTATCTAG3'; WSSV146Rv1: 5' TAATGCGGGT GT A A T G T T C T T A C G3' (fragmento 1.447pb);WSSV146Fw2:5'GTAACTGCC CCTTCCATCTCCA3'; e WSSV146Rv2: 5'TACGGC AGCTGCTGCACCTTGT3' (fragmento $941 \mathrm{pb}$ ). As duas etapas de amplificação consistiram de $94^{\circ} \mathrm{C}$ por $4 \mathrm{~min}, 55^{\circ} \mathrm{C}$ por $1 \mathrm{~min}, 72^{\circ} \mathrm{C}$ por $2 \mathrm{~min}$, seguidos por 39 ciclos $\left(94^{\circ} \mathrm{C}\right.$ por $1 \mathrm{~min}, 55^{\circ} \mathrm{C}$ por $1 \min$ e $72^{\circ} \mathrm{C}$ por $2 \mathrm{~min}$ ) com extensão final a $72^{\circ} \mathrm{C}$ por 5 min. Todos os produtos de $\mathrm{PCR}$ foram analisados em gel de agarose (1\%) corado com brometo de etídeo $\left(0,5 \mu \mathrm{g} \mathrm{mL}^{-1}\right)$.

Além da análise por PCR convencional, a presença do vírus também foi investigada por PCR em tempo real nos animais sobreviventes do grupo dsRNA vp28/W+, após 30 dias do desafio. Para tanto,

Pesq. agropec. bras., Brasília, v.48, n.8, p.983-990, ago. 2013 DOI: 10.1590/S0100-204X2013000800025 
utilizou-se o kit DyNAmo SYBR Green qPCR Finnzymes, (Thermo Fisher Scientific, Waltham, MA, EUA), a partir de 100 ng de DNA genômico. Os iniciadores utilizados referem-se a uma sequência da proteína do envelope viral vp19 - VP19Fw: 5'ATGGCCACCACGACTAACACT3'; e VP19Rv: 5'CTGCCTCCTCTTGGGGTA3' (fragmento $375 \mathrm{pb}$ ) (Genbank: EU012447). As condições da reação foram $95^{\circ} \mathrm{C}$ durante $10 \mathrm{~min}$, seguidos por 40 ciclos de $95^{\circ} \mathrm{C}$ por $20 \mathrm{~s}, 58^{\circ} \mathrm{C}$ por $20 \mathrm{~s} \mathrm{e} 72^{\circ} \mathrm{C}$ por $20 \mathrm{~s}$.

Os resultados obtidos da contagem total de hemócitos nos diferentes grupos foram submetidos à análise de variância, e as médias foram comparadas pelo teste de Tukey, a 5\% de probabilidade. As análises foram realizadas no programa Statistica 7 (StatSoft, Inc., Tulsa, OK, EUA).

\section{Resultados e Discussão}

Os animais não tratados com dsRNA vp28, mas injetados com WSSV (grupo $\mathrm{W}+$ ), apresentaram o vírus em seu organismo já nas 6 horas após o desafio, enquanto, nos animais previamente tratados com dsRNA (grupo dsRNA vp28/W+), o vírus foi detectado somente por "nested" PCR e a partir de 48 horas do desafio (Tabela 1), o que indica poucas partículas virais nesses animais. Estes resultados também são indicativos de que a estimulação do sistema RNAi nos animais antes do desafio viral induz as defesas antivirais específicas contra o WSSV, o que limita a evolução da infecção viral de maneira importante. Essa hipótese foi confirmada, uma vez que, nos animais desafiados, mas não tratados com dsRNA vp28, a taxa de mortalidade foi de $100 \%$ cinco dias após o desafio (Figura 2). No entanto, nos camarões tratados, a

Tabela 1. Detecção do vírus da síndrome da mancha-branca (WSSV), por PCR convencional em um $(+)$ ou dois passos ("nested"-PCR) (++), a partir de DNA genômico extraído de um "pool" de três animais por grupo.

\begin{tabular}{lccccc}
\hline Tratamento $^{(1)}$ & \multicolumn{5}{c}{ Horas pós-injeção } \\
\cline { 2 - 6 } & 3 horas & 6 horas & 24 horas & 48 horas & 72 horas \\
\hline $\mathrm{W}-$ & - & - & - & - & - \\
$\mathrm{W}+$ & - & ++ & + & + & + \\
dsRNA vp28/W+ & - & - & - & ++ & ++ \\
\hline
\end{tabular}

(1)(W-), não tratados com dsRNA vp28 e injetados com inóculo negativo; $(\mathrm{W}+)$, não tratados com dsRNA vp28 e injetados com inóculo positivo; dsRNA vp28/W+, tratados com dsRNA vp28 e injetados com inóculo positivo. mortalidade foi de apenas $27 \%$, o que resultou em $73 \%$ de sobrevivência durante os 30 dias do experimento. As análises individuais desses sobreviventes, por PCR em tempo real, revelaram a presença do vírus somente em $20 \%$ dos camarões. Tanto as elevadas taxas de sobrevivência (73\%), quanto a ausência do vírus em $80 \%$ dos sobreviventes, mostram claramente que o tratamento prévio com a dose utilizada de dsRNA vp28 ( $1 \mu \mathrm{g}$ dsRNA vp28 por $3 \mathrm{~g}$ de peso vivo) foi efetiva e capaz de induzir o sistema antiviral via RNAi em L. vannamei. Esse tratamento levou ao controle específico da infecção por WSSV em sua fase inicial, o que promoveu "clearance" viral no organismo da maioria dos camarões sobreviventes.

Resultados semelhantes foram relatados por Mejía-Ruíz et al. (2011), que, ao utilizar o mesmo dsRNA e a mesma dose, observaram atividade antiviral em juvenis de L. vannamei, por 30 dias, em $50 \%$ dos animais, e que os sobreviventes também não apresentavam mais o vírus no organismo.

O grau de proteção conferido por dsRNAs específicos varia entre os diferentes genes virais alvo, o que indica

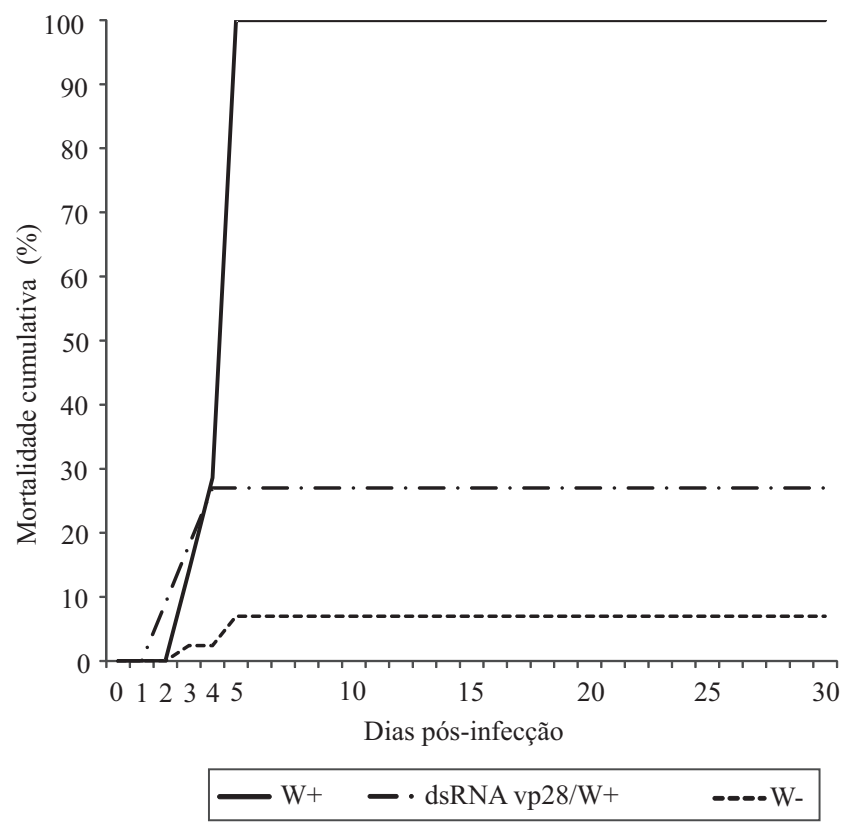

Figura 2. Taxa de mortalidade cumulativa de camarões marinhos (Litopenaeus vannamei), em cada tratamento, durante 30 dias. $(\mathrm{W}+)$, não tratados com dsRNA vp28 e injetados com inóculo positivo; dsRNA vp28/W+, tratados com dsRNA vp28 e injetados com inóculo positivo; (W-), não tratados com dsRNA vp28 e injetados com inóculo negativo. 
que a escolha do gene alvo é um fator limitante no sucesso da supressão da infecção viral (Robalino et al., 2005). Kim et al. (2007) demonstraram que camarões injetados com dsRNA correspondentes aos genes da vp28 e da proteína quinase (proteína não estrutural do WSSV) apresentam maior taxa de sobrevivência do que quando injetados com dsRNA da vp281, outra proteína do envelope do WSSV. A vp28, uma das principais proteínas do envelope do WSSV, é uma das responsáveis pela entrada do vírus nas células do hospedeiro e deve ser sintetizada junto ao vírion para que o processo de infecção se efetive. Uma vez que a síntese da vp28 é bloqueada via RNAi, a ocorrência dos processos de infecção e replicação virais é virtualmente limitada ou interrompida, como mostrado no presente trabalho e em outros anteriores (Robalino et al., 2005; Kim et al., 2007; Xu et al., 2007; Sarathi et al., 2008; Mejía-Ruíz et al., 2011).

Com relação à quantidade de dsRNA vp28 para induzir RNAi em camarões, há diferentes relatos na literatura. Kim et al. (2007) obtiveram taxa de sobrevivência de $100 \%$ (sete dias) em Penaeus chinensis infectados com altas doses de WSSV e previamente injetados com alta dose de dsRNA vp28 ( $1 \mu \mathrm{g} \mathrm{g}^{-1}$ de peso vivo). De forma semelhante, Robalino et al. (2005) relataram sobrevivência de 85\% (nove dias) em pós-larvas de L. vannamei injetadas com WSSV e tratadas previamente com uma dose de dsRNA vp28 de $12 \mu \mathrm{g}$ por 1 a $2 \mathrm{~g}$ de peso vivo. Já os resultados do presente trabalho e os de Mejía-Ruíz et al. (2011) mostraram que a dose de $1 \mu \mathrm{g}$ por $3 \mathrm{~g}$ do mesmo constructo molecular (dsRNA vp28) foi suficiente para induzir as defesas contra o WSSV em L. vannamei cultivados no Brasil e no México.

Efetivamente, a dose utilizada está dentro da faixa recomendada por diversos estudos com camarões (1-5 $\mu \mathrm{g}$ de dsRNA por animal), para limitar de maneira satisfatória a replicação de diferentes vírus e diminuir significativamente a mortalidade dos animais (Shekhar $\& \mathrm{Lu}, 2009)$.

Somente os animais tratados com dsRNA vp28 sobreviveram à infecção por WSSV e permaneceram vivos durante os 30 dias de experimento, apesar de $20 \%$ deles ainda apresentarem o vírus no organismo. Isso mostra que o tratamento prévio dos camarões com dsRNA vp28 levou ao controle da infecção viral em sua fase inicial e promoveu "clearance" viral na maioria dos sobreviventes. Dessa maneira, esse constructo molecular poderá ser utilizado em programas de terapia antiviral, de caráter preventivo contra o WSSV, em camarões cultivados.

Quanto às condições de saúde e ao hemograma dos animais, observou-se que o número de hemócitos circulantes foi reduzido em todos os tratamentos até 6 horas pós-inoculação, independentemente da injeção ou não com o vírus (Figura 3). Relatos de diminuições no hemograma de camarões que sofreram estresse por injeções de qualquer natureza são comuns e podem estar associados à infiltração dos hemócitos no local da injúria (Sarathi et al., 2007).

Nos grupos desafiados, houve redução no hemograma de cerca de 4x (W+) e 5x (dsRNA vp28/ $\mathrm{W}+$ ) ainda nas 6 horas. Já no grupo desafiado, não tratado com dsRNA vp28, essa redução foi progressiva e drástica, tendo alcançado um valor extremamente baixo $\left(5,3 \times 10^{6}\right.$ células $\left.\mathrm{mL}^{-1}\right)$, cerca de seis vezes inferior ao do controle $\left(31 \times 10^{6}\right.$ células $\left.\mathrm{mL}^{-1}\right)$, no terceiro dia (72 horas) pós-infecção (Figura 3). Esses resultados são indicativos da rápida evolução na infecção viral no organismo e da grande debilidade imunológica nos animais, a qual culminou em 100\% de mortalidade dos camarões em cinco dias (Figura 2).

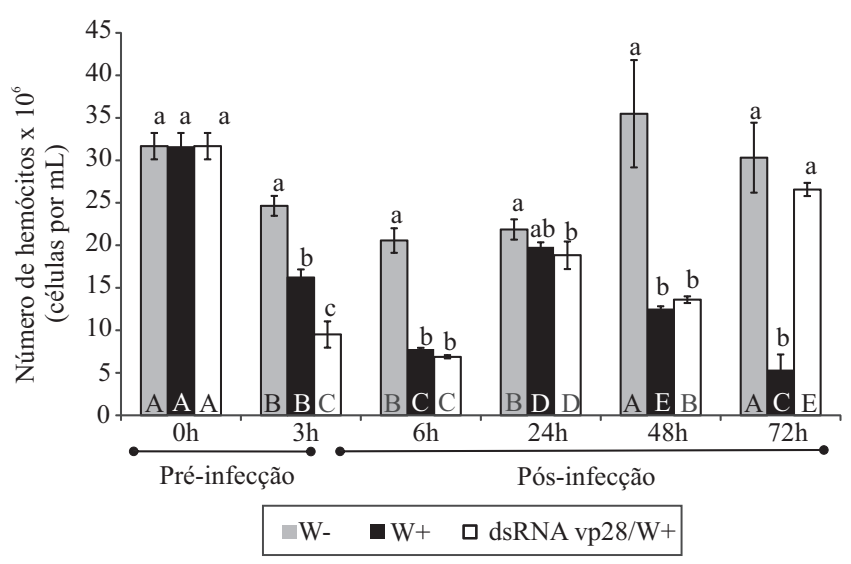

Figura 3. Contagem total de hemócitos (CTH) em camarões marinhos (Litopenaeus vannamei) às $0,3,6,24,48$ e 72 horas pós-infecção com inóculo negativo (W-) ou positivo (W+ e dsRNA vp28/W+) para o vírus da síndrome da mancha-branca (WSSV). Médias seguidas de letras iguais maiúsculas, na CTH dentro de um mesmo grupo nos diferentes períodos analisados, não diferem pelo teste de Tukey, a 5\% de probabilidade. Médias seguidas de letras iguais minúsculas, na CTH entre os grupos dentro de um mesmo período, não diferem pelo teste de Tukey, a 5\% de probabilidade. 
Entretanto, nos animais em que as defesas antivirais foram previamente induzidas via RNAi (dsRNA vp28/ $\mathrm{W}+)$, o hemograma retornou ao nível normal $\left(27 \times 10^{6}\right.$ células $\mathrm{mL}^{-1}$ ) 72 horas pós-desafio (Figura 3). Isso mostra que houve recuperação nas condições gerais de saúde dos animais, o que possibilitou que novas células imunocompetentes (hemócitos) fossem produzidas pelo tecido hematopoiético.

Em contrapartida, a queda brusca e crescente do hemograma nos camarões apenas desafiados com WSSV indicou que a depleção dos hemócitos circulantes está diretamente associada à replicação viral dentro das células. Os hemócitos são um dos principais sítios de replicação do WSSV (Wang et al., 2002) e diversos trabalhos já mostraram que ocorre diminuição significativa no hemograma em camarões infectados (Sarathi et al., 2007; Yeh et al., 2009).

Sarathi et al. (2007) observaram queda no hemograma de Fenneropenaeus indicus após infecção severa com WSSV associada tanto à lise, quanto à apoptose celulares. Embora os fenômenos de lise e apoptose celulares não tenham sido investigados no presente trabalho, sabe-se que estes fenômenos são comuns em infecções virais e que podem ter ocorrido. Contudo, a redução significativa no hemograma do grupo $\mathrm{W}+$, em estágios mais avançados da infecção (72 horas pós-desafio), pode, também, estar relacionada à diminuição na produção dos hemócitos pelos órgãos hematopoiéticos. Em estudos com outro decápoda, o lagostim Pacifastacus leniusculus, constatou-se que células do tecido hematopoiético podem ser infectadas por WSSV, com prejuízo ao funcionamento do órgão e, consequentemente, à produção de novos hemócitos (Jiravanichpaisal et al., 2006).

O tratamento prévio de juvenis de L. vannamei com dsRNA vp28, na concentração utilizada no presente trabalho, mostrou-se eficaz para induzir resposta antiviral contra o WSSV, via RNAi. A alta taxa de sobrevivência e a restituição das boas condições imunológicas dos animais desafiados indicam que o tratamento com dsRNA vp28 levou ao controle da infecção viral em sua fase inicial, limitou-a e promoveu "clearance" viral em $80 \%$ dos sobreviventes. Dessa maneira, o dsRNA vp28 poderia ser utilizado, mediante estudos futuros de viabilidade econômica, como agente terapêutico para prevenir e limitar infecções por WSSV em camarões.

O mecanismo antiviral baseado na técnica de RNAi atualmente representa a abordagem terapêutica melhor fundamentada, efetiva e promissora no controle das viroses em crustáceos cultivados. Apesar da aplicação prática da tecnologia de RNAi ainda ser inviável na carcinicultura, em razão dos elevados custos e da dificuldade de aplicação nos animais por via sistêmica, estudos recentes apontam para uma adaptação menos onerosa da técnica e outros modos de administração, para viabilizar a sua utilização em larga escala dentro da carcinicultura.

\section{Conclusões}

1. Camarões marinhos (Litopenaeus vannamei) infectados severamente com o vírus da síndrome da mancha-branca (WSSV), mas não tratados com dsRNA vp28, apresentam queda significativa na quantidade de hemócitos circulantes e não sobrevivem ao desafio viral.

2. O tratamento com dsRNA vp28 limita a infecção por WSSV, aumenta a taxa de sobrevivência e mantém as boas condições imunológicas dos camarões por meio do restabelecimento do número de hemócitos circulantes (hemograma).

3. O tratamento com dsRNA vp28 controla a infecção viral em sua fase inicial, limita-a e promove a ausência do vírus na maioria dos sobreviventes.

4. A concentração de dsRNA vp28 de $1 \mu \mathrm{g}$ por $3 \mathrm{~g}$ de peso vivo é eficaz para estimular o sistema RNAi em juvenis de L. vannamei e induz resposta antiviral específica contra o WSSV.

\section{Agradecimentos}

À Financiadora de Estudos e Projetos (Finep), pelo auxílio financeiro; à Coordenação de Aperfeiçoamento de Pessoal de Nível Superior (Capes), pela concessão de bolsa; a Edemar Roberto Andreatta, Walter Seiffert e Felipe Vieira, do Laboratório de Camarões Marinhos da Universidade Federal de Santa Catarina (UFSC), pelo fornecimento dos camarões marinhos; e a Delano Dias Schleder, do Instituto Federal Catarinense (IFC), Araquari, pelo apoio nos experimentos com desafio.

\section{Referências}

ALIYARI, R.; DING, S.-W. RNA-based viral immunity initiated by the Dicer family of host immune receptors. Immunological Reviews, v.227, p.176-188, 2009. DOI: 10.1111/j.1600-065X.200 8.00722.x. 
BARRACCO,M.A.;PERAZZOLO,L.M.;ROSA,R.D.Inmunología del camarón. In: MORALES, Q.V.; CUÉLLAR-ANJEL, J. (Ed.). Patología y inmunología de camarones penaeidos: guía técnica. Panamá: CYTED, 2008. p.169-224.

BEÇAK, W.; PAULETE, J. Técnicas de citologia e histologia. Rio de Janeiro: Liv. Técnicos e Científicos, 1976. 327p.

CHEN, L.L.; WANG, H.C.; HUANG, C.J.; PENG, S.E.; CHEN, Y.G.; LIN, S.J.; CHEN, W.Y.; DAI, C.F.; YU, H.T.; WANG, C.H.; LO, C.F.; KOU, G.H. Transcriptional analysis of the DNA polymerase gene of shrimp white spot syndrome virus. Virology, v.301, p.136-147, 2002. DOI: 10.1006/viro.2002.1536.

CHOU, H.Y.; HUANG, C.Y.; WANG, H.; CHIANG, H.C.; LO, C.F. Pathogenicity of a baculovirus infection causing white spot syndrome in cultured penaeid shrimp in Taiwan. Diseases of Aquatic Organisms, v.23, p.165-173, 1995. DOI: 10.3354/ dao023165.

ESCOBEDO-BONILLA, C.M.; ALDAY-SANZ, V.; WILLE, M.; SORGELOOS, P.; PENSAERT, M.B.; NAUWYNCK, H.J. A review on the morphology, molecular characterization, morphogenesis and pathogenesis of white spot syndrome virus. Journal of Fish Diseases, v.31, p.1-18, 2008. DOI: 10.1111/j.13 65-2761.2007.00877.x.

HANNON, G.J. RNA interference. Nature, v.418, p.244-251, 2002. DOI: $10.1038 / 418244$ a.

JIRAVANICHPAISAL， P.; LEE, B.L.; SÖDERHÄLL, K. Cell-mediated immunity in arthropods: hematopoiesis, coagulation, melanization and opsonization. Immunobiology, v.211, p.213-236, 2006. DOI: 10.1016/j.imbio.2005.10.015.

KIM, C.S.; KOSUKE, Z.; NAM, Y.K.; KIM, S.K.; KIM, K.H. Protection of shrimp (Penaeus chinensis) against white spot syndrome virus (WSSV) challenge by double-stranded RNA. Fish and Shellfish Immunology, v.23, p.242-246, 2007. DOI: 10.1016/j.fsi.2006.10.012.

LO, C.F.; HO, C.H.; PENG, S.E.; CHEN, C.H.; HSU, H.C.; CHIU, Y.L.; CHANG, C.F.; LIU, K.F.; SU, M.S.; WANG, C.H.; KOU, G.H. White spot syndrome baculovirus (WSBV) detected in cultured and captured shrimp, crabs and other arthropods. Diseases of Aquatic Organisms, v.27, p.215-225, 1996. DOI: 10.3354/ dao027215.

MAYO, M.A. A summary of taxonomic changes recently approved by ICTV. Archives of Virology, v.147, p.1655-1663, 2002. DOI: 10.1007/s007050200039.

MEJÍA-RUÍZ, C.H.; VEGA-PEÑA, S.; ALVAREZ-RUIZ, P.; ESCOBEDO-BONILLA, C.M. Double-stranded RNA against white spot syndrome virus (WSSV) vp28 or vp26 reduced susceptibility of Litopenaeus vannamei to WSSV, and survivors exhibited decreased susceptibility in subsequent re-infections. Journal of Invertebrate Pathology, v.107, p.65-68, 2011. DOI: 10.1016/j.jip.2011.02.002.

MÜLLER, I.C. Genes diferencialmente expressos em camarões de cultivo Litopenaeus vannamei infectados pelo vírus da Síndrome da Mancha Branca e genotipagem de isolados geográficos brasileiros do vírus. 2009. 150p. Tese (Doutorado) Universidade Federal de Santa Catarina, Florianópolis.
OBBARD, D.J.; GORDON, K.H.J.; BUCK, A.H.; JIGGINS, F.M. The evolution of RNAi as a defence against viruses and transposable elements. Philosophical Transactions of the Royal Society. Biological Sciences, v.364, p.99-115, 2009. DOI: 10.1098/ rstb.2008.0168.

WORLD ORGANISATION FOR ANIMAL HEALTH. Manual of diagnostic tests for aquatic animals. $5^{\text {th }} \mathrm{ed}$. Paris: OIE, 2006. 469p. Available at: <http://www.oie.int/doc/en_document. php?numrec=3667303>. Accessed on: 15 Feb. 2010.

PRIOR, S.; BROWD, C.L.; SHEPARD, E.F.; LAMORE, R.; PARNELL, P.G. Controlled bioassay systems for determination of lethal infective doses of tissue homogenates containing Taura syndrome or white spot syndrome virus. Diseases of Aquatic Organisms, v.54, p.89-96, 2003. DOI: 10.3354/dao054089.

ROBALINO, J.; BARTLETT, T.; SHEPARD, E.; PRIOR, S.; JARAMILLO, G.; SCURA, E.; CHAPMAN, R.W.; GROSS, P.S.; BROWDY, C.L.; WARR, G.W. Double-stranded RNA induces sequence-specific antiviral silencing in addition to nonspecific immunity in a marine shrimp: convergence of RNA interference and innate immunity in the invertebrate antiviral response? Journal of Virology, v.79, p.13561-13571, 2005. DOI: 10.1128/ JVI.79.21.13561-13571.2005.

SARATHI, M.; AHMED, V.P.I.; VENKATESAN, C.; BALASUBRAMANIAN, G.; PRABAVATHY, J.; HAMEED, A.S. Comparative study on immune response of Fenneropenaeus indicus to Vibrio alginolyticus and white spot syndrome virus. Aquaculture, v.271, p.8-20, 2007. DOI: 10.1016/j.aquaculture.2007.07.002.

SARATHI, M.; SIMON, M.C.; VENKATESAN, C.; HAMEED, A.S. Oral administration of bacterially expressed VP28dsRNA to protect Penaeus monodon from white spot syndrome virus. Marine Biotechnology, v.10, p.242-249, 2008. DOI: 10.1007/ s10126-007-9057-6.

SEIFFERT, W.Q.; BELTRAME, E.; ANDREATTA, E.R.; MAGGIONI, D.S. Enfermidades de camarões: uma boa oportunidade para repensar o cultivo. Panorama da Aquicultura, v.16, p.32-38, 2006.

SHEKHAR, M.; LU, Y. Application of nucleic-acid-based therapeutics for viral infections in shrimp aquaculture. Marine Biotechnology, v.11, p.1-9, 2009. DOI: 10.1007/ s10126-008-9155-0.

VAN HULTEN, M.C.W.; WITTEVELDT, J.; PETERS, S.; KLOOSTERBOER, N.; TARCHINI, R.; FIERS, M.; SANDBRINK, H.; LANKHORST, R.-K.; VLAK, J.M. The white spot syndrome virus DNA genome sequence. Virology, v.286, p.7-22, 2001. DOI: 10.1006/viro.2001.1002.

WANG, Y.T.; LIU, W.; SEAH, J.N.; LAM, C.S.; XIANG, J.H.; KORZH, V. White spot syndrome virus (WSSV) infects specific hemocytes of the shrimp Penaeus merguiensis. Diseases of Aquatic Organisms, v.52, p.249-259, 2002. DOI: 10.3354/dao052249.

WONGTEERASUPAYA, C.; VICKERS, J.E.; SRIURAIRATANA, S.; NASH, G.L.; AKARAJAMORN, A.; BOONSAENG, V.; PANYIM, S.; TASSANAKAJON, A.; WITHYACHUMNARNKUL, B.; FLEGEL, T.W. A non-occluded, systemic baculovirus that occurs in cells of ectodermal and mesodermal origin and causes high mortality in the black tiger 
prawn Penaeus monodon. Diseases of Aquatic Organisms, v.21, p.69-77, 1995. DOI: 10.3354/dao021069.

XU, J.; HAN, F.; ZHANG, X. Silencing shrimp white spot syndrome virus (WSSV) genes by siRNA. Antiviral Research, v.73, p.126-131, 2007. DOI: 10.1016/j.antiviral.2006.08.007.

YANG, F.; HE, J.; LIN, X.; PAN, D.; ZHANG, X.; XU, X. Complete genome sequence of shrimp white spot bacilliform virus.
Journal of Virology, v.75, p.11811-11820, 2001. DOI: 10.1128/ JVI.75.23.11811-11820.2001.

YEH, S.-P.; CHEN, Y.-N.; HSIEH, S.-L.; CHENG, W.; LIU, C.-H. Immune response of white shrimp, Litopenaeus vannamei, after a concurrent infection with white spot syndrome virus and infectious hypodermal and hematopoietic necrosis virus. Fish and Shellfish Immunology, v.26, p.582-588, 2009. DOI: 10.1016/j. fsi.2008.09.010.

Recebido em 25 de julho de 2011 e aprovado em 31 de maio de 2013 